This item was submitted to Loughborough's Research Repository by the author.

Items in Figshare are protected by copyright, with all rights reserved, unless otherwise indicated.

\title{
The impact of user- and system-initiated personalization on the user experience at large sports events
}

PLEASE CITE THE PUBLISHED VERSION

http://dx.doi.org/10.1016/j.apergo.2015.11.001

PUBLISHER

(C) Elsevier

VERSION

AM (Accepted Manuscript)

\section{PUBLISHER STATEMENT}

This work is made available according to the conditions of the Creative Commons Attribution-NonCommercialNoDerivatives 4.0 International (CC BY-NC-ND 4.0) licence. Full details of this licence are available at: https://creativecommons.org/licenses/by-nc-nd/4.0/

\section{LICENCE}

CC BY-NC-ND 4.0

\section{REPOSITORY RECORD}

Sun, Xu, Andrew May, and Qingfeng Wang. 2015. "The Impact of User- and System-initiated Personalization on the User Experience at Large Sports Events”. Loughborough University. https://hdl.handle.net/2134/19650. 


\title{
The impact of user- and system-initiated personalization on the user experience at large sports events
}

Xu Sun* [Xu.sun@nottingham.edu.cn, 008657488186443]

Product Design and Manufacture Group, Faculty of Engineering, University of Nottingham China, Ningbo, 315100, China

Andrew May [a.j.may@lboro.ac.uk]

Loughborough Design School, Loughborough University, Ashby Road, Loughborough, LE11 3TU, UK

Qingfeng Wang [Qingfeng.wang@nottingham.edu.cn]

Department of Quantitative and Applied Economics, Nottingham University Business School, University of Nottingham, Ningbo, 315100, China

\begin{abstract}
This article describes an experimental study investigating the impact on user experience of two approaches of personalization of content provided on a mobile device, for spectators at large sports events. A lab-based experiment showed that a system-driven approach to personalization was generally preferable, but that there were advantages to retaining some user control over the process. Usability implications for a hybrid approach, and design implications are discussed, with general support for countermeasures designed to overcome recognised limitations of adaptive systems.
\end{abstract}

\section{Keywords}

User studies, Personalization, User Experience, UX, Large Sports Event 


\section{Introduction}

Although large sports events are a rich and dynamic social and information environment, several studies have shown that the spectator experience at such events can be improved, e.g. at football matches, athletics meetings and swimming galas. Spectators can find it hard to access and assimilate the diversity of information present within a stadium (Sun and May, 2007).

Esbjornsson et al. (2006) describe the 'viewers paradox' encountered by sports spectators: although an event provides a rich experience, it is often difficult to put what is observed into the broader context, for example what a lap means for a particular race, an individual performance for a team, or the implications of a game for a wider competition. In addition, many sporting events are characterised by long periods of waiting. This can result in boredom for the spectator, but also an opportunity to support an active engagement with the event, and to treat an event as a 'resource for conversation' amongst spectators. Over a decade ago Olsson and Nilsson (2002) showed how much of the social interaction between spectators at events is actually quite limited and inactive. Even recent research such as Ko et al. (2011) has highlighted that the social experience should be enhanced at major spectator sports events.

Personalized services and information have been proposed to accommodate individual differences at sports events (Macquet and Stanton, 2014). Userinitiated personalization and system-initiated personalization are two scalable approaches to the design of personalization (Fan and Poole, 2006). User-initiated personalization is described as the adjustment of a system, initiated by the user to achieve a desired goal (Sundar and Marathe, 2010). By contrast, system-initiated personalization refers to the adjustment initiated by a system, based on a user profile, to guide content delivery according to what the user is believed to be interested in (Arora et al., 2008). The balance of user-initiated and system personalization is essential for personalization to work effectively.

A number of studies (e.g. Martinez et al., 2009; Verpoorten et al., 2009; Sun and May, 2013) have shown that both user-generated and system-generated personalization have benefits within specific usage environments. 'Usergenerated' and 'system-generated' personalization are roughly equivalent to the terms 'adaptable' and 'adaptive used in the user modelling literature - i.e 
either allowing users themselves to adapt content and layout to their preferences, or having a system undertake this automatically (Treiblmaier et al., 2004).

Jameson (2005) has highlighted that although system-generated personalization approaches (user-adaptive systems) have specific advantages, they have been shown to have a number of usability implications which may compromise their benefits, and that the best overall design is very context dependent. Hybrid approaches to personalization or adaptation have been proposed (e.g. Tsandilas and Schraefel, 2004; Park et al., 2007), but there is currently still a lack of understanding of the specific benefits that each approach brings (Kwon and Kim, 2012), and how this approach can be applied in large sports environments

The main aim of this article is to study a specific usage environment (large sports events) and assess the potential for personalized mobile content to enhance the UX for a spectator. The benefits of both user and system-generated approaches within this environment are investigated, and the results discussed in terms of the challenges above and the usability of a hybrid approach that capitalises on the merits of each.

\section{Previous work}

\subsection{Personalization}

Fan and Poole (2006) highlight how personalization means different things to different people in different fields. This makes it difficult to compare and contrast studies. Bonnet (2001), from a marketing perspective, suggests that personalization can recreate the human element that understands the customer and offers a 'personalized touch', and concludes that the ultimate aim of personalization is user satisfaction. Norman (2004) suggests that 'we are all designers' - and that users inherently want to personalize. Users can create a more engaging user experience by organising their thoughts, memories, and images that they find useful or pleasing. It has even been proposed by Christos et al. (2005) that the majority of mobile users think of it as a declaratory part of their personality.

Customization is another commonly used term in previous studies. 'Personalization' and 'customization' have numerous definitions that are sometimes used interchangeably in the literature (Sunikka1 and Bragge, 2012). Personalization research has a strong focus on technology and the internet, 
emphasizing customers' needs and preferences, as well as information collection for user modelling (Kwon et al., 2010). Customization has traditionally focused on tangible products but has lately initiated research in service fields which emphasises the user's role in specifying content (Montgomery and Smith, 2009). Sundar and Marathe (2010) suggest that the key difference between personalization and customization is that personalization is system-initiated, whereas customization is user-initiated.

This article uses the general term of personalization, and (contrary to Sundar and Marathe, 2010) makes the distinction between user-initiated personalisation and system-initiated personalisation. It employs the people-centred perspective of Kwon and Kim (2012) to define personalization based on understanding users' context-dependent preferences, goals and behaviours - therefore being able to satisfy their needs, and enhance their UX.

This article focuses on content personalization (Wu et al., 2003) which provides tailored information within a particular node within the human-device navigation space. This is based on the key assumption that the optimal content for an individual is dependent on contextual factors relating to the individual, their activities and their situation, and that these factors can be used as the input or triggers for the adaptation of content for the individual (Norros et al., 2003) in order to enhance their UX. The aim of this paper is not to discuss how different forms of personalization may come about, which can be through a variety of approaches such as dynamic adaptation models or prediction, classification, clustering, association rule mining and sequential pattern discovery (Kiu and Tsui, 2011); instead this article seeks to show differences in user outcomes based on whether this personalization is essentially instigated by the user, or by the 'system'.

Despite a number of studies investigating better information provision to spectators at large sports events (e.g. Lim et al., 2009), there has been a lack of research into the role that personalized content plays in enhancing the UX within this specific environment. However, the benefits of personalization have been shown in a number of other scenarios - e.g. tourist guides (Souffriau et al., 2008), office applications (Bergman et al., 2004), e-commerce (Georgiadis, 2005), and learning systems (Economides, 2009). Although personalization (in its broadest sense) undoubtedly provides benefits, the evidence is not wholly unequivocal. For example, Loboda and Brusilovsky (2010) investigated educational applications 
employing personalized and non-personalized explanatory visualizations. Although students preferred the application which adapted learning content according to level of understanding, they found no difference in short term knowledge gain between the two applications.

There have been relatively few studies that compare empirically the impact of user or system-initiated approaches. Some have found favour with user-initiated personalization and its focus on the natural intelligence of the user (Sundar and Marathe, 2010). Similarly, Coner (2003) found that user-initiated approaches were more effective for website personalization. Whilst user-initiated personalization is considered appropriate in many cases, most users actually fail to personalize effectively (Weld et al., 2003). Few are comfortable responding to requests to set personalization parameters, and individuals can spend time inputting personalization data that actually turns out to have little impact on them. Jameson (2005) describes how desirable usability goals are often threatened by the typical properties of user-adaptive systems (i.e. personalization which is system-initiated). He also highlights that although there are trade-offs between desired usability goals, the best overall design solution is very dependent on the user or their situation.

Martinez et al. (2009) found that users performed better with, and reacted more positively to system-initiated personalization within digital libraries. In contrast, Park et al. (2007) examined the effectiveness of user-initiated and system-initiated menus in desktop applications. The results of a controlled study showed that the user-initiated menu was the best in terms of both performance and satisfaction. User-initiated menus provided a sense of control, and maximised the efficiency of interaction. The authors concluded that a hybrid combination of the user and system menus would be interesting future research. Verpoorten et al. (2009), within a learning environment, also highlighted the support that user-initiated personalization provides for perceived controllability and self-efficacy.

Much previous work on personalization - e.g. Park et al. (2007), Verpoorten et al. (2009) - has focussed on relatively static information environments, where the contextual inputs used for system-initiated personalization may vary between users, but are relatively static for a specific individual. Therefore although this work can highlight the potential benefits of different personalization approaches, it may have limited applicability to a highly dynamic environment such as a large 
sports event, where the focus of attention is away from a mobile device, and there are scheduled and unscheduled temporal tensions (Tamminen et al., 2004).

\subsection{User experience (UX)}

The term 'user experience' in this paper refers to the subjective experience that a spectator encounters within a stadium (Sun and May, 2007). Jameson (2005) has highlighted the usability trade-offs that occur when automatic adaptation of systems occurs. UX is a broader concept than usability, reflecting the fact that mobile devices are personal artefacts used by individuals with particular social and cultural norms, within an external context defined by their environment (Chamorro-Koca et al., 2009). At sports events, UX is defined by the spatial bounds of the stadium, and arises as a result of the interactions that occur between the individual and other entities within the stadium. These interactions can be between the user and the sporting action, the user and other individuals (including the crowd), the user and other information sources, and the user and their mobile device.

There is much discussion of the nature and scope of UX within HCI (e.g. Roto et al., 2011); however there is general consensus that it is subjective, dynamic and context-dependent (Law and Sun, 2012). ISO9241-110:2010 defines UX as 'A person's perceptions and responses that result from the use and/or anticipated use of a product, system or service'. Hassenzahl and Tractinsky (2006) define UX as 'a consequence of a user's internal state (predispositions, expectations, needs, motivation, mood, etc.), the characteristics of the designed system (e.g. complexity, purpose, usability, functionality, etc.) and the context (or the environment) within which the interaction occurs (e.g. organisational/social setting, meaningfulness of the activity, voluntariness of use, etc.)'.

Many different perspectives on UX have evolved and a universal definition of UX is difficult to establish (Zahariasa and Mehlenbacher, 2012). Existing theories of user experience are useful at a general level; however, they are too general to be used as a practical tool in product design or the concept design context. Rasmussen (2000) argues that as society becomes more dynamic and integrated with technology, there is a need for greater multidisciplinarity in tackling human factor problems. Therefore a range of literature is useful in terms of identifying the user experience components that can be employed within a people-centred design process. 


\section{Method}

\subsection{Overview}

This study was undertaken as a laboratory experiment, following on from three field studies to identify the context at a range of large sports events (Sun and May, 2009; 2013). This experiment tried to address the problems of conventional lab usability testing by recreating or imitating a realistic context of use in the laboratory, and using participants who were familiar with a large sports event environment. Participants completed five spectator scenarios, and UX was measured according to key components, described below.

\subsection{UX definition}

This research follows the UX distinction made by Arhippainen and Tähti (2003). In evaluating mobile application prototypes, they describe five categories of influences on the user experience evoked through the interaction with a device, relating to user, social, cultural, context of use, and product (i.e. device). By focusing on the influences, rather than the consequences (Hassenzahl and Tractinsky, 2006) or perceptions/responses (ISO 2010) it is easier to understand the role played by the wide range of contextual factors (including product and cultural) within situated use, and the reasons for participant responses.

A total of seven prior field trials with participants at large sports events (Sun and May, 2007; 2010) investigated and validated the UX main and sub-components that were relevant to this study. These were: (1) user aspect (users' emotions, needs and expectations in relation to a product or service); (2) social aspect (the users' perception of their social engagement in the large sports event, and the sense of creating and sharing experiences at large sports events); (3) usage context aspect (the extent the stadium environment supports spectator activities such as watching the sporting action and enabling social interaction); (4) culture aspect (the key relevant values and traditions of the user group - these being group image, group belonging and group interaction for the spectators); and (5) product aspect (perceived ease of use, and perceived usefulness).

The principle of employing the mixed-method approach is particularly relevant for UX, given that it is inherently subjective and highly dynamic (Law and Sun, 2012). Law and van Schaik (2010) describe how UX needs to be self-reported, 
since it is a personal and experiential quality, in contrast to the goal and task orientation of more established usability measures. Therefore UX was measured in relation to each of the above constructs using a series of Likert scales, based on the components and subcomponents outlined above. The scales are shown in Appendix 1. Three items were employed for each of the five components of UX, and an even (six-point) scale to force participants to commit to either side of a neutral response, as recommended by Ramscar (2008).

\subsection{Participants}

A set of eighteen participants took part in the study, aged between 18 and 38, and split equally male-female, with various occupations. They were recruited in the UK. Participants were screened to have the same level of personalization experience (i.e. frequency of personalization on an application) and spectating records at LSEs (i.e. number of attendance at LSEs) to avoid different perceptions prior to the experiment (Lavie et al., 2011). All participants had regular experience of personalising mobile devices, and had attended a large sports event within the last six months.

\subsection{Experimental environment}

This study was a laboratory study which enabled greater control of variables, following the general rationale of Rieman (1993). It was based on a multi-event athletics meeting as it presented a visually challenging environment for a spectator due to multiple simultaneous events. The usability lab was set up to resemble part of a sports stadium and incorporated the factors that had been found in Sun and May (2009) to have most impact on UX, shown in Appendix II. Sports footage recorded at an athletics meeting, including auditory output, was projected onto the front wall of the laboratory, creating an image of $5.7 \mathrm{~m}$ wide by $2.7 \mathrm{~m}$ high. A crowd scene was replicated on each of the two side walls by a projected image on one side and five A0 size posters on the other side. A pilot study had suggested that a more immersive environment (i.e. left and right projected crowd scenes) was too distracting for participants, and drew their attention away from the main projected sporting scene. Participants sat $5 \mathrm{~m}$ away from the projected scene and a video camera was set behind to record users' interaction with the simulations (Figure 1). 


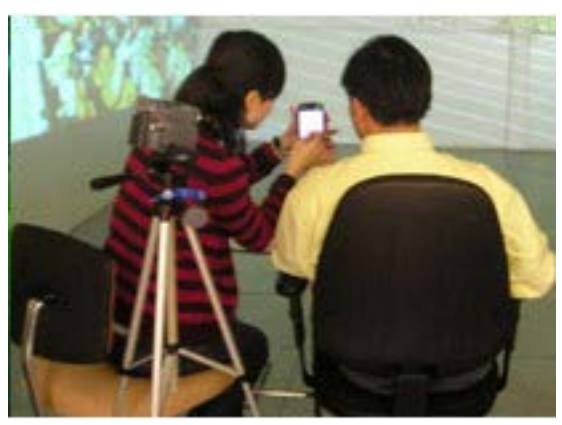

Figure 1. Scene projection and participant video recording

\subsection{Experimental conditions}

Three methods of presenting content to participants were employed. A control condition was used to replicate the paper-based programme normally available at sports events, and provide a base level benchmark. The paper leaflet was designed at the level of what a user could usually obtain during a real event. It provided information on competition times and athlete information in a consistent format (i.e. colour and font) of content via mobile applications.

A user-initiated condition presented event-related information to the participant, and allowed them to personalize the information as described by Sun et al. (2015). The effect of personalization was to provide more detailed information on the athletes of interest, including their recent performance and a schedule of events that they were taking part in.

A system-initiated condition presented tailored information to the participant using a simulation developed in ActionScript as previously, and with a similar look and feel. This simulation did not require input from the participant, and simulated the automatic adaptation of content according to key personalization parameters: sporting preferences; event progress; spectator location. The effect of these personalization parameters is shown in Table 1 below.

The system-initiated simulation was configured by collecting data on sporting interests from the participants prior to the study, without this being overt, or revealing the reason for doing so. Content according to the user's interests and preferences was then specifically created within the simulation, and programmed to appear at the relevant stages within the scenarios. This created the impression that the application was adapting automatically to the interests of the individual spectator. 
Dynamic personalization according to event progress was simulated by prematching presented content to the sporting action being viewed by the participant at that point in the experiment. During peak moments (e.g. climaxes of events) only summary information was presented, whereas during lulls in the sporting action, more detailed information was presented to the participants. During this study, participants were also able to select their position in the simulated stadium, which then created the impression of selecting the optimum video feed for the spectator (see Table 1 below).

Five scenarios were developed, each incorporating a key spectator activity as before. Four of the activities were the same as those employed in a previous field study (Sun et al., 2015), but tailored to an athletics meeting. This experiment also employed a fifth activity which required the participant to select preferred simulated real-time video feeds, enabling them to follow the sporting action irrespective of their location in the stadium (Figure 2).

Table 1. Summary of scenarios used in empirical studies.

\begin{tabular}{|c|c|c|}
\hline Spectator scenario & Function provided & $\begin{array}{l}\text { Personalization } \\
\text { parameter }\end{array}$ \\
\hline $\begin{array}{l}\text { Checking the schedule } \\
\text { of forthcoming athletic } \\
\text { events and finding one } \\
\text { of particular interest }\end{array}$ & $\begin{array}{l}\text { Information on event } \\
\text { schedules, including } \\
\text { timetables and event } \\
\text { locations }\end{array}$ & $\begin{array}{l}\text { Selection of event and } \\
\text { athlete preferences } \\
\text { (sporting interests) }\end{array}$ \\
\hline $\begin{array}{l}\text { Obtaining information } \\
\text { on a particular athlete of } \\
\text { interest (static } \\
\text { information access) }\end{array}$ & $\begin{array}{l}\text { Information on the } \\
\text { athletes participating in } \\
\text { the event }\end{array}$ & $\begin{array}{l}\text { Selection of event and } \\
\text { athlete preferences }\end{array}$ \\
\hline $\begin{array}{l}\text { Reviewing the progress } \\
\text { of the current events } \\
\text { (dynamic information } \\
\text { access) }\end{array}$ & $\begin{array}{l}\text { Real time } \\
\text { summaries }\end{array}$ & $\begin{array}{l}\text { Event progress - } \\
\text { categorising peaks } \\
\text { and lulls in the } \\
\text { sporting action }\end{array}$ \\
\hline $\begin{array}{l}\text { Joining a virtual } \\
\text { 'community' within the } \\
\text { stadium. }\end{array}$ & $\begin{array}{l}\text { Online chat and media } \\
\text { sharing within a simulated } \\
\text { virtual community. }\end{array}$ & $\begin{array}{l}\text { Selection of event and } \\
\text { athlete preferences }\end{array}$ \\
\hline a suitable & Optimized viewings of the & Spectator \\
\hline
\end{tabular}


viewing angle for a live action broadcast via the mobile device. sporting action based on (row and

their location in the number) stadium.

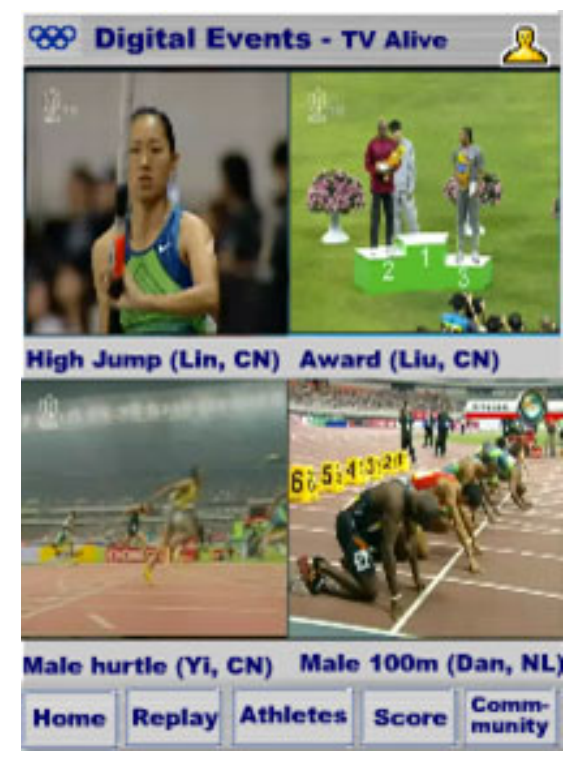

Figure 2. Selection of mobile broadcasts

\subsection{Procedure}

Prior to the study, participants were asked for general background information, including sporting interests. This was used to pre-configure the simulation of system initiated personalization, as described above.

Each participant was in turn introduced to the concept of personalization, and given instruction on how to use the mobile simulation. They were told that one simulation would require them to enter personalization parameters in order to obtain tailored information, whereas the other would automatically present tailored information to them.

Each of the five scenarios was completed in turn, using each of the three information sources. For each instance of user-initiated personalization, participants clicked on a button which provided access to a personalization page. For the system-initiated personalization, the information summarised in Table 1 was presented automatically to the participant, without any need for user input. The order of the presentation of the personalization factor was balanced across the participants for each task. 
As each participant completed a scenario with one of the information sources, they were asked to pick an Emotion Card (Desmet, 2000) that best represented their experience, and to explain their choice. The emotion cards were used as reflective aids, rather than data collection tools. Participants were encouraged to think aloud throughout using verbal protocols (Ryan and Haslegrave, 2007). Having completed the range of spectator activities, they were again shown the two forms of simulation and the paper programme. Participants then completed the 15 item questionnaire for each of the three information sources. The study lasted approximately one hour for each participant.

\subsection{Analysis of data}

Friedman non-parametric tests for three related samples were calculated for the main within-subjects factors. Multiple paired comparisons were undertaken using the technique described in Siegel and Castellan (1988, p.180), to take into account the increased likelihood of a type I error with multiple comparisons.

The observational data, concurrent verbal reports and interview transcripts were analyzed using an affinity diagram technique (Hackos and Redish, 1998). Quantitative and qualitative data are presented below, and participant quotes are included to exemplify some of the points. Participant quotes have been preserved as a literal (rather than grammatically correct) translation from Chinese to English in order to retain the nuances within the statements.

\section{Results and discussion}

\subsection{Quantitative results}

Figure 3 shows the impact of content presentation according to three information sources (system-initiated personalization; user-initiated personalization; control condition) on components of UX. Ratings are based on six-point scales, from 'strongly disagree' (1) to 'strongly agree' (6), and the error bars represent 95\% confidence intervals (C.I.) of the mean in all cases, as before. 


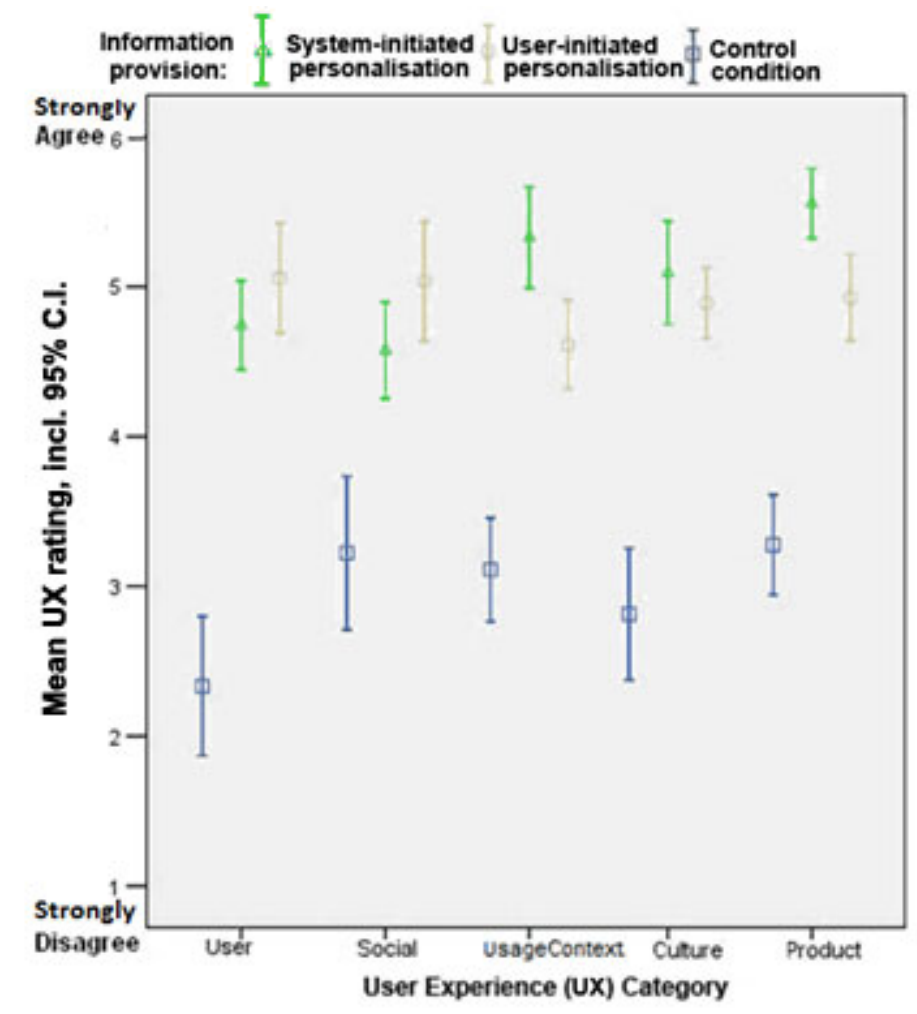

Figure 3. Impact of system and user initiated personalization

\subsection{Qualitative results}

The results section below (and the following discussion) highlights the comparison between user and system-initiated personalization approaches.

Table 2. Summary of participants' (nos. 1-18) experience under the two test conditions

\begin{tabular}{lll}
\hline UX Factors & $\begin{array}{l}\text { User-initiated } \\
\text { personalized prototype }\end{array}$ & $\begin{array}{l}\text { System-initiated } \\
\text { personalized prototype }\end{array}$ \\
\hline User aspect: & $\begin{array}{l}\text { It gave user full control } \\
\text { over the information. It } \\
\text { provided flexibility and } \\
\text { information variety. }\end{array}$ & $\begin{array}{l}\text { It was quick and } \\
\text { effortless to use during } \\
\text { the event, but sometimes } \\
\text { missed the real interests } \\
\mid R_{\text {system-initiated }}-R_{\text {use-initiated }}\end{array}$ \\
$=7.5<\mathrm{Z}=14.36, \mathrm{~N}=18$, & $\begin{array}{l}\text { of a user. } \\
\text { mowever, it required too }\end{array}$ & $\begin{array}{l}\text { Participants: 2, 3, 7, 11, } \\
\text { no significant difference settings. }\end{array}$ \\
& $\begin{array}{l}\text { Participants: } 1,4,5,8,9, \\
12\end{array}$ & \\
& &
\end{tabular}




\begin{tabular}{|c|c|c|}
\hline $\begin{array}{l}\text { Social aspect: } \\
\begin{array}{l}\left|R_{\text {system-initiated }}-R_{\text {use-initiated }}\right| \\
=4.5,<\mathrm{Z}=14.36 \\
\mathrm{~N}=18, \text { no significant } \\
\text { difference }\end{array}\end{array}$ & $\begin{array}{l}\text { It encouraged social } \\
\text { interaction by allowing } \\
\text { control and freedom of } \\
\text { choice whom to interact } \\
\text { with. } \\
\text { Participants: 4, 5, 9, } 12\end{array}$ & $\begin{array}{l}\text { It enhanced social } \\
\text { interaction by assigning } \\
\text { users to a certain group } \\
\text { without effort and } \\
\text { providing rapid } \\
\text { communication. } \\
\text { Participants: 5, 6, 7, 11, } \\
18\end{array}$ \\
\hline $\begin{array}{l}\text { Usage context aspect: } \\
\begin{array}{l}\left|R_{\text {system-initiated }}-R_{\text {use-initiated }}\right| \\
=15,>\mathrm{Z}=14.36^{*} \text {, } \\
\mathrm{N}=18 \text {, system-initiated } \\
\text { prototype was } \\
\text { significantly higher }\end{array}\end{array}$ & $\begin{array}{l}\text { It could accommodate } \\
\text { users' instantaneous } \\
\text { interest during an event. } \\
\text { Participants: 4, 12, } 16\end{array}$ & $\begin{array}{l}\text { It provided relevant } \\
\text { information in good time. } \\
\text { It could quickly help } \\
\text { users to become familiar } \\
\text { with the environment. } \\
\text { Participants: } 2,3,5,6 \text {, } \\
7,9,11,13,14,18\end{array}$ \\
\hline $\begin{array}{c}\left|R_{\text {system-initiated }}-R_{\text {use-initiated }}\right| \\
=1,<\mathrm{Z}=14.36, \mathrm{~N}=18, \\
\text { no significant difference }\end{array}$ & $\begin{array}{l}\text { It allowed users to choose } \\
\text { a group of people in } \\
\text { common and emphasized } \\
\text { the group image during } \\
\text { the events. It brought a } \\
\text { greater sense of control, } \\
\text { satisfaction. } \\
\text { Participants: } 1,3,4,17\end{array}$ & $\begin{array}{l}\text { It assigned users to a } \\
\text { group of people with } \\
\text { common interests and } \\
\text { emphasized the group } \\
\text { image during the events. } \\
\text { Participants: } 2,3,7,12 \text {, } \\
18\end{array}$ \\
\hline \multirow[t]{2}{*}{$\begin{array}{l}\text { Product aspect: } \\
\left|R_{\text {system-initiated }}-R_{\text {use-initiated }}\right| \\
=18,>\mathrm{Z}=14.36^{*}, \\
\mathrm{~N}=18, \text { system-initiated } \\
\text { prototype was } \\
\text { significantly higher }\end{array}$} & $\begin{array}{l}\text { It needed some time and } \\
\text { effort to set up, but it can } \\
\text { consider users' actual } \\
\text { interest and brought a } \\
\text { sense of familiarity with } \\
\text { the mobile product. }\end{array}$ & $\begin{array}{l}\text { It was quick and } \\
\text { effortless to operate. } \\
\text { However it could be } \\
\text { confusing when it did not } \\
\text { match a user's actual } \\
\text { interest. }\end{array}$ \\
\hline & Participants: 1, 8, 4, 12 & $\begin{array}{l}\text { Participants: 2, 5,6, 7, 8, } \\
9,11,14,15,18\end{array}$ \\
\hline
\end{tabular}

User aspect: The user-initiated personalization engendered in the participants a sense of control (Nielsen, 1998), and satisfied the desire to have one's choices rather than environmental events determine one's action (Oulasvirta and Blom, 2008), a typical quote is:

\#4 - 'I want the feeling of being in control by setting the preferences and getting the results of what I have set' 
Users preferred a product over which they had control of preferences, rather than having the product personalize on their behalf, based on implicit preferences. Participants expressed the feeling of autonomy (including volition) is reduced by system-initiated personalization.

User-initiated personalization also provided more flexibility for participants accessing information. It could take into account the transient nature of spectator preferences, but required time and visual attention to set new preferences, a typical quote is:

\#4 - 'I won't be happy to use it just before results are announced!'

System-initiated personalization, on the other hand, responded to users' expectations of quick, effortless and relevant information during the event). It appeared to be an 'intelligent facilitator', especially during climaxes in the sporting action, for example:

\#7 - 'It is just as I expected, providing me with the right information at the right time'

There was a concern among participants that they could miss the transient interest of a user.

Social aspect: Both personalization approaches helped to demonstrate opportunities for socializing with spectators sharing common interests. In addition, both approaches allowed sharing of group information instead of individual information, which helps mitigate privacy concerns. Rather than communicating with others using a mobile application, participants wanted to have a 'facilitator' to create and promote actual face-to-face communication - i.e. real interaction promoted through virtual interaction. A typical quote is:

\#13 - 'I like it if the personalization can propose a communication topic of common interest to fellow spectators nearby.'

User-initiated personalization gave participants full control over finding potential 'friends' (within the simulation) according to their preferences at the athletics events (including being able to deal with a user's transient interests). The systeminitiated approach did not support the participants' sense of being in control; however it allowed participants to instantly share their feelings by automatically assigning them to a group of users with common interests For example:

\#3 - 'I would like to share my thoughts instantly now, I do not care who I am talking to. The point is sharing, not to reach understanding.' 
An interesting finding was that both personalized mobile simulations demonstrated the potential for acting as an ice breaker with fellow spectators by providing a topic of common interest. For example, the mobile prototypes provided detailed information on player information that had just scored. This implied a latent requirement of participants:

\#5 - 'If someone (unknown) also receives this information (player information), we can start a conversation on this topic. It will be interesting to talk to those share the common interests and values with me’.

Usage context aspect: Both personalization approaches helped participants to overcome the limitations of the stadium (e.g. providing additional views of the event, and promoting wider social interaction). System, rather than user-initiated personalization was preferred because it quickly and effortlessly enabled users to become comfortable with an unfamiliar environment. Participants liked to be guided automatically in these circumstances. A typical quote is:

\#9 - 'I first prefer to be guided automatically till I understand the overall environment.'

System-initiated personalization was also able to make information available while taking into account the temporal tensions (Tamminen et al., 2004) taking place in the stadium, for example:

\#9 - 'Winner information and results is only what I care about now.'

Cultural aspect (group belonging): Both personalization approaches were equally effective in demonstrating the formation of groups with an emphasised group image (Figure 3). Note that the simulation demonstrated how social groupings could be formed based on personal interests - it did not enable participants to actually interact with others. User-initiated personalization demonstrated to participants that they could select their preferred community (e.g. those shown as sitting nearby), enhancing the sense of control, privacy and engagement. A typical quote is:

\#17 - 'I enjoy choosing the group to socialize with'.

In contrast, the system-initiated personalization demonstrated faster sharing of experiences in the stadium, and some participants felt their group to be 'special' due to it being 'chosen' intelligently by the technology:

$\# 12$ - 'I like my group: we share common values and it was chosen by 'fate'!' 
Product aspect: In terms of usability, users preferred the system-initiated personalization approach (Figure 3) because it was quick and effortless, supporting the findings of Perkowitz and Etzioni (2000), a typical quote is:

\#8 - 'It provides me the right information instantly!'

However, the system-initiated personalization simulation traded-off speed and convenience with lack of control. Users wanted to be able to tailor schedules based on short-term variation in their interests, and retain control over this process, for example:

\#15 - 'I would like to know the personalization parameters and to be able to change them whenever I like'

\section{General discussion}

\subsection{Different approaches to personalization of a mobile application}

The study above has shown that user and system-driven approaches both provided distinct benefits within the sports context. User-driven personalization was found to be more accurate and engendered a feeling of control, whereas a system-driven approach minimised the effort required from the participant. Since the approach in this study was based on covert identification of participants' actual preferences, and prior modelling of the interaction environment, the results relating to systeminitiated personalization were able to focus on the impact of automatic adaption, rather than be confounded by the technical limitations of preference and context discovery. As a result, the negative effects of imprecise personalization (Markellos et al., 2009) were minimised within this study.

The quantitative and qualitative data both highlight the advantages of systemdriven personalization (i.e. automatic adaptation). User ratings of usage context and product UX aspects showed a significant superiority of system initiated personalization in situations of the attention 'costs' of user interaction are relatively high (e.g. during sporting climaxes). However, there were still some clear advantages to user-initiated personalization in situations where it doesn't matter to the end user whether they interact with an application now or later. The study suggests that a hybrid approach is beneficial, as it can incorporate user input for choices which are non-computable and potentially highly transient, and where the interaction costs are low in relation to variance in the possible outcomes. 
Hybrid systems can make information available while taking into account that the design solution that yields the best overall balance may different sharply from one user or situation to the next (Jameson, 2005). The findings of the current study, and specific design proposals, are discussed below in relation to some of these countermeasures.

\section{\#1 Allow user to set parameters that control the system's behaviour}

Supported by this research and previous research (Sun and May, 2009; 2013). Specific user preferences (e.g. an interest in a specific team) are one of the most influential factors in determining how a system can enhance the UX. Where these preferences are strong and stable (e.g. as evidenced by holding of a season ticket), system-driven personalization based on this factor is likely to enhance the UX. However, in line with Ciborra and Lanzara (1994), some preferences were also shown to be short-term and transient, favouring user input to personalization.

\section{\#2 Adapt timing of messages to users' activities and context}

Supported, but not limited to 'timing'. Event progress (for want of a better term) was developed as a temporal categorisation of an event, encompassing the concepts of 'temporal tensions' (Tamminen et al., 2004) and spectator engagement in the sporting action. It relates to periods that can be defined as 'preevent', 'lulls', 'sporting climaxes', 'pauses' and 'post-event', and is a critical influence on the need for information, the willingness of a spectator to interact with a device, and the UX. The timing of 'messages' (i.e. content) is obviously key. However, an additionally important aspect of this countermeasure is the need for adaptation of level of detail in the supplied content. In addition, the desirable balance between user and system driven adaptation appeared to shift according to the level of engagement modelled according to event progress. When a user is pre-occupied with the sporting action, automatic personalization is needed in order to provide tailored information without the need for user input. At other times, user-initiated personalization provides more control and flexibility over content/functionality provision, and can help alleviate moments of boredom.

\section{\#3 Shift control to system gradually, as competence increases}

Conflicting evidence. If competence is defined as the match between the required and the available skills and knowledge of the individual, then one aspect of competency refers to the ability to find your way around a sports stadium and understand the sporting action. Participants described how system-initiated 
personalization was useful in large, unfamiliar environments, whereas they may prefer to take more control over personalization of content within a more familiar sporting environment. Participants will develop familiarity within a given sports environment, and hence a shift in control from system to user may be appropriate.

\subsection{Limitations}

This study focuses on exploring the impact on user experience of difference approaches of mobile content personalization at large sports events. The investigation of the evaluation methodology between the two empirical studies was reported in Sun and May (2013). There some limitations to this study. The first relates to the Likert Scales used to assess the components of the UX. These were developed directly from the literature on UX in order to measure individual aspects of UX (Arhippainen and Tähti, 2003; Hassenzahl and Tractinsky, 2006; Law and Sun, 2012). However the qualitative data identified that there were more subtle factors at play resulting in pros and cons for both user and system-initiated personalization; these were not differentiated by the level of granularity within the scales. The second limitation relates to how personalization was incorporated into the study using only three factors (sporting preferences, physical location and event progress). Although previous field studies (Sun and May, 2009) had indicated these were the most important, a range of other factors influence the functionality and content that is appropriate for a spectator within a situated context. Finally, the studies purposively employed a multi-methods approach, combining both a positivist and interpretivist perspective. The advantage of this was it allowed a measurement of differences in outcomes arising from the different experimental conditions, plus a richer understanding of how and why those measured differences occurred. The disadvantage was that the aims of the study were then exposed to the participants. A possible result of this was that for each study, the more sophisticated condition was automatically rated more highly by participants. However, this is not borne out by Figure 3, or the qualitative data which identified benefits and drawbacks of the more sophisticated condition within each of the studies. 


\section{Acknowledgements}

This work was carried out as part of the Philips Research program on Lifestyle. The authors acknowledge financial support from National Natural Science Foundation of China programme (grant No. 71401085).

\section{References}

Arhippainen, L., Tähti, M. (2003). Empirical Evaluation of User Experience in Two Adaptive Mobile Application Prototypes. The 2nd international conference on mobile and ubiquitous multimedia, Sweden.

Arora, N., Dreze, X., Ghose, A., Hess, J.D., Iyengar, R., Jing, B., Joshi, Y., Kumar, V., Lurie, N., Neslin, S., Sajeesh, S., Su, M., Syam, N., Thomas, J., Zhang, Z.J. (2008) Putting one-to-one marketing to work: personalization, customization and choice. Marketing Letters, Vol. 19 (3-4), 305-321.

Bergman, O., Boardman, R., Gwizdka, J., Jones, W. (2004). Personal Information Management. CHI 2004 Special Interest Group, Vienna, Austria, ACM.

Bonnet, M. (2001). Personalization of web services: opportunities and challenge. Available from: http://www.ariadne.ac.uk/issue28/personalization, last accessed on 23 October 2015.

Chamorro-Koca, M., Popovica, V., Emmison, M. (2009). Human experience and product usability: Principles to assist the design of user-product interactions. Applied Ergonomics, Vol. 40 (4), 648-656.

Christos K., G., Mavridis, I., Manitsaris, A. (2005). Context-based humanized and authorized personalization. University of Macedonia, Greece.

Ciborra, C.U., Lanzara, G. F. (1994). Formative Contexts and Information Technology: Understanding the dynamics of innovation in organizations. Accounting, Management and Information Technology, Vol. 4 (2), 61-86.

Coner, A. (2003). Personalization and Customization in Financial Portals. Journal of American Academy of Business, Vol.2 (2), 498-504.

Desmet, P.M.A. (2000). Emotion through expression: designing mobile telephones with an emotional fit. Report of Modeling the Evaluation Structure of KANSEI, Vol. 3, 103-110. 
Economides, A.A. (2009). Adaptive Context-aware Pervasive and Ubiquitous Learning. International Journal of Technology Enhanced Learning, Vol.1 (3), 169-192.

Fan, H., Poole, M.S. (2006). What is personalization? Perspectives on the design and implementation of personalization in information systems. Journal of Organizing Computing and Electronic Commerce, Vol. 16 (3-4), 179-202.

Fernandes, T. (1995). Global Interface Design. Massachusetts: Academic Press.

Georgiadis, C. K., Mavridis, I., Manitsaris, A. (2005). Context-based Humanized and Authorized Personalization in Mobile Commerce Applications. International Journal of Computing \& Information Sciences, Vol.3 (2), 1-9.

Hackos, J., Redish, J. (1998). User and Task Analysis for Interface Design. New York: Wiley.

Hassenzahl, M., Tractinsky, N. (2006). User experience - a research agenda. Behaviour and information technology, Vol. 25 (2), 91-97.

ISO 9241-210. (2010). Ergonomics of Human-System Interaction-Part 210: Human centred Design for Interactive Systems

Jameson, A. (2005). User Modeling Meets Usability Goals. In L. Ardissono, P. Brna, \& A. Mitrovic (Eds.), UM2005, User modeling: Proceedings of the Tenth International Conference (pp. 1-3). Berlin: Springer.

Kiu, C.C., Tsui, E. (2011) TaxoFolk: A hybrid taxonomy-folksonomy structure for knowledge classification and navigation. Expert Systems with Applications, Vol. 38(5), 6049-6058.

Ko, Y.J., Zhang,J., Cattani,K., Pastore,D. (2011) Assessment of event quality in major spectator sports. Managing Service Quality, Vol. 21 (3), 304-322.

Kwon, K., Cho, J., Park, Y. (2010) How to best characterize the personalization construct for e-services. Expert Systems with Applications, Vol. 37 (3), 22322240 .

Kwon, K., Kim, C. (2012) How to design personalization in a context of customer retention: Who personalizes what and to what extent?. Electronic Commerce Research and Applications, Vol.11 (2), 101-116. 
Lavie, T., Oron-Gilad, T., Meyer, J. (2011). Aesthetics and usability of in-vehicle navigation displays. International Journal of Human-Computer Studies, Vol. 69 (1), 80-99.

Law, E. L-C., van Schaik, P. (2010) Modelling user experience - An agenda for research and practice. Interacting with Computers, Vol. 22 (5), 313-322.

Law, E., Sun, X. (2012) Evaluating user experience of adaptive digital educational games with Activity Theory. International Journal of Human-Computer Studies, Vol. 70, (7), 478-497.

Lim, S., Park, C., Cha, S.Y., Moon, J., Lee, I., Kim, J. (2009) The role of eventdriven social media and dynamic sports broadcasting system as crowd computing media. Crowd Computer Interaction CHI2009, Boston, MA.

Loboda, T. D., Brusilovsky, P. (2010). User-adaptive explanatory program visualization: evaluation and insights from eye movements. User Modeling and User-Adapted Interaction, Vol. 20 (3), 191-226.

Macquet,A. C., Stanton, N.A. (2014). Do the coach and athlete have the same picture of the situation? Distributed Situation Awareness in an elite sport context. Applied Ergonomics, Vol. 45(3), 724-733.

Martinez, E. F., Chen, S. Y., Liu, X. H. (2009). Evaluation of A Personalized Digital Library based on Cognitive Styles: Adaptivity vs. Adaptability. International Journal of Information Management, Vol. 29 (1), 48-56.

Montgomery, A.M., Smith, M.D. (2009). Prospects for personalization on the internet. Journal of Interactive Marketing, Vol. 23 (2), 130-137.

Norman, D.A. (2004). Emotional design: why we love (or hate) everyday things. New York: Basic Books.

Norros, L., Kaasinen, E., Plomp, J., Rama, P. (2003). Human-Technology Interaction Research and Design. VTT roadmap, VTT research notes 2220, Espoo, Finland.

Olsson, D., Nilsson, A. (2002). Mep: a media event platform. Mobile networks and applications. Mobile Networks and Applications, Vol. 7 (3), 235-244.

Oulasvirta, A., Blom, J. (2008). Motivations in personalization behaviour. Interacting with Computers, Vol. 20 (1), 1-16. 
Park, J., Han, S.H., Park, Y.S., Cho, Y. (2007). Adaptable versus adaptive menus on the desktop: Performance and user satisfaction. International Journal of Industrial Ergonomics, Vol. 37(8), 675-684.

Ramscar, M. (2008). When might you not use a 7-point scale?. Available from: http://www psych.stanford.edu/ lera/290/scale.html, retrieved on 11 April 2010.

Rasmussen, J. (2000). Human Factors in a Dynamic Information Society: Where Are We Heading?. Ergonomics, Vol.43 (7), 869-879.

Rieman. J. (1993). The diary study: a workplace-oriented research tool to guide laboratory efforts. The CHI conference on Human factors in computing systems (CHI '93). ACM, 321-326.

Roto, V., Law, E., Vermeeren, A., Hoonhout, J. (2011). User Experience White Paper. Outcome of the Dagstuhl Seminar on Demarcating User Experience, Germany. Available from: http://www.allaboutux.org/uxwhitepaper, last accessed on 23 October 2015.

Ryan, B., Haslegrave, C. M. (2007). Use of concurrent and retrospective verbal protocols to investigate workers' thoughts during a manual-handling task. Applied Ergonomics, Vol. 38 (2), 177-190.

Siegel, S., Castellan, N.J. (1988). Nonparametric statistics for the behavioral sciences. New York: McGraw-Hill.

Souffriau, W., Vansteenwegen, P., Vertommen, J., Berghe, G.V., Oudheusden, D.V. (2008). A personalized tourist trip design algorithm for mobile tourist guides. Applied Artificial Intelligence: An International Journal, Vol. 22 (10), 964-985.

Sundar, S.S., Marathe, S.S. (2010) Personalization versus Customization: The Importance of Agency, Privacy, and Power Usage. Human Communication Research, Vol. 36 (3), 298-322.

Sunikka1, A., Bragge, J. (2012) Applying text-mining to personalization and customization research literature - Who, what and where?. Expert Systems with Applications, Vol.39 (11), 10049-10058.

Sun, X., May, A. (2007). Mobile personalization at large sports events - user experience and mobile device personalization. Usability and Internationalization. Global and Local User Interfaces Lecture Notes in Computer Science Vol. 4560, 486-495. 
Sun, X., May, A. (2009). The role of spatial contextual factors in mobile personalization at large sports events. Personal and Ubiquitous Computing, Vol. 13(4), 293-315.

Sun, X., May, A. (2013). A Comparison of Field-Based and Lab-Based Experiments to Evaluate User Experience of Personalised Mobile Devices, Advances in Human-Computer Interaction, Vol. 2013, Article ID 619767

Sun, X., May, A., Wang Q. (2015). Investigation of the Role of Mobile Personalisation at Large Sports Events. To appear in International Journal of Mobile Human Computer Interaction.

Tamminen, S., Oulasvirta, A., Toiskallio, K., Kankainen, A. (2004). Understanding mobile contexts. Personal and ubiquitous computing, Vol. 8(2), 135-143.

Treiblmaier, H., Madlberger, M., Knotzer, N., Pollach, I. (2004). Evaluating personalization and customization from an ethical point of view: An empirical study. In Proceedings of the 37th Hawaii International conference on System Sciences.

Tsandilas, T., Schraefel, M.C. (2004). Usable Adaptive Hypermedia Systems. New Review of Hypermedia and Multimedia, Vol.10 (1), 5-29.

Verpoorten, D., Glahn, C., Kravcik, M., Ternier, S., Specht, M. (2009). Personalization of Learning in Virtual Learning Environments. In U. Cress, V. Dimitrova \& M. Specht (Eds.), Learning in the Synergy of Multiple Disciplines, LNCS 5794. Berlin and Heidelberg, Germany.

Wu, D., Im, I., Tremaine, M., Instone, K., Turoff, M. (2003). A framework for classifying personalization schemes used on e-commerce websites. The HICSS 36th Hawaii International Conference on Systems Sciences, Hawaii.

Zahariasa,P., Mehlenbacher, B. (2012). Exploring User Experience (UX) in virtual learning environments. International Journal of Human-Computer Studies. Vol. 70(7), 475-477. 


\section{Appendix I - Likert items used to assess UX}

In all cases, participant responses were based on a six point scale ranging from 1 (Strongly disagree) to 6 (Strongly agree)

Substitute A, B or C in the items below as follows
A: the user-initiated prototype
B: the system-initiated prototype
C: the paper-based information

User aspect:

1. I feel happy ${ }^{1}$ using [A / B / C] during the event

2. My expectations ${ }^{2}$ regarding my spectator experience in the stadium are met using $[\mathrm{A} / \mathrm{B} / \mathrm{C}]$

3. My needs as a spectator are taken into account using [A / B / C]

Social aspect:

4. Using [A / B / C] helps me feel I am communicating, and sharing information with others in the stadium

5. The [A / B / C] helps me create enjoyable experiences within the stadium

6. The [A / B / C] helps me share my experiences with others within the stadium Usage context aspect:

7. The $[\mathrm{A} / \mathrm{B} / \mathrm{C}]$ provides me with help in the stadium while watching the sporting action

8. The [A / B / C] provides me with information about other spectators in the stadium

\footnotetext{
1 In Chinese, the translation of 'happy' includes notions of 'cheerfulness' and 'contentment'

2 In Chinese, the translation of 'expectations' includes the notion of 'hope'
} 
9. The [A / B / C] helps provide me with a good physical and social environment in the stadium

Culture aspect:

10. The [A / B / C] helps me feel part of a group

11. The $[\mathrm{A} / \mathrm{B} / \mathrm{C}]$ helps me promote the image of my group

12. The $[\mathrm{A} / \mathrm{B} / \mathrm{C}]$ helps me interact with my group

Product aspect:

13. The $[\mathrm{A} / \mathrm{B} / \mathrm{C}]$ is useful at the event

14. The $[\mathrm{A} / \mathrm{B} / \mathrm{C}]$ is easy to learn how to use

15. The $[\mathrm{A} / \mathrm{B} / \mathrm{C}]$ is easy to use

1 In Chinese, the translation of 'happy' includes notions of 'cheerfulness' and 'contentment'

2 In Chinese, the translation of 'expectations' includes the notion of 'hope' 


\section{Appendix II - Contextual Factors}

The table shows the contextual factors that were shown by prior field studies to have the greatest influence on the preferred content for spectators. Factors were either controlled for, or incorporated as personalization parameters, as below:

\begin{tabular}{|c|c|}
\hline Contextual factor & Approach \\
\hline $\begin{array}{l}\text { Sporting preferences of } \\
\text { the spectator }\end{array}$ & $\begin{array}{l}\text { Incorporated: in user and } \\
\text { system initiated } \\
\text { simulations, used to tailor } \\
\text { content }\end{array}$ \\
\hline $\begin{array}{l}\text { Spectator location in the } \\
\text { stadium }\end{array}$ & $\begin{array}{l}\text { Incorporated: in user and } \\
\text { system initiated } \\
\text { simulations, used to } \\
\text { obtain tailored broadcasts }\end{array}$ \\
\hline Event progress & $\begin{array}{l}\text { Incorporated: in user and } \\
\text { system initiated } \\
\text { simulations, used to tailor } \\
\text { content }\end{array}$ \\
\hline Event types & $\begin{array}{l}\text { Controlled: athletics } \\
\text { events }\end{array}$ \\
\hline Language & Controlled: Mandarin \\
\hline With whom & $\begin{array}{l}\begin{array}{l}\text { Controlled: with } \\
\text { researcher } \\
\text { representations of } \\
\text { and } \\
\text { spectators }\end{array} \\
\end{array}$ \\
\hline Mobile screen & $\begin{array}{l}\text { Controlled: screen size } \\
9 \mathrm{~cm} \text { diagonal, } 800 \times 480 \\
\text { pixels }\end{array}$ \\
\hline Public media channels & $\begin{array}{l}\text { Controlled: recorded } \\
\text { audio from a sports event }\end{array}$ \\
\hline $\begin{array}{l}\text { Spectators' sports } \\
\text { knowledge/experience }\end{array}$ & $\begin{array}{l}\text { Controlled: } \\
\text { knowledge only }\end{array}$ \\
\hline Social atmosphere & $\begin{array}{l}\text { Controlled: simulated } \\
\text { spectators plus recordings } \\
\text { of audience sound }\end{array}$ \\
\hline
\end{tabular}

